\title{
Reflexões acerca da construção dos direitos humanos e seu diálogo com o marxismo
}

Reflections on the construction of human rights and their dialogue with Marxism

\section{Rafaela Ribeiro Saraiva da Costa*}

\begin{abstract}
Resumo - O presente artigo tem como objetivo refletir sobre os direitos humanos a partir da exposição das determinações histórico-sociais que incidem sobre a aquisição histórica e processual dos direitos. Buscaremos realizar uma interlocução com a crítica marxiana, tecida no ensaio $A$ questão judaica (1844), que aponta os limites postos à sociedade burguesa e a restrição dos direitos no campo da emancipação política.

Palavras-chave: direitos; direitos humanos; emancipação política; emancipação humana.
\end{abstract}

\begin{abstract}
This article aims to reflect on human rights from the exposition of historical and social determinations that affect the historical and procedural acquisition of rights. We will seek to establish a dialogue with the marxian critique, woven in the essay The Jewish Question (1844) which points out the limits placed on bourgeois society and the restriction of rights in the field of political emancipation.

Keywords: rights; human rights; political emancipation; human emancipation.
\end{abstract}

\section{Breve recuperação histórica das lutas por incorporação de direitos}

Para que as ideias transformadoras se concretizem na realidade faz-se necessárío que existam condições sociais e históricas que favoreçam as mudanças. É preciso também que os grupos sociais consigam resistir às pressões dos seus oponentes. Diante dessas exigências, é difícil reunir todos esses elementos em um momento específico e concreto, mas, no caso dos direitos humanos, tais fatores estavam minimamente combinados em alguns países da Europa Ocidental, no século XVIII, e, em particular, na França. Essas forças foram gestadas durante um longo período da história e não se deram de forma imediata, mas processual. Por esse motivo, a compreensão

\footnotetext{
* Mestranda em Serviço Social pela Universidade Federal de Pernambuco (UFPE). Assistente Social do Instituto de Medicina Integral Professor Fernando Figueira. Correspondência: Rua Quarenta e Três, 24, São Francisco Cabo de Santo Agostinho - PE. CEP: 54530-530. Email: <rafinhasaraivach@gmail.com>.
} 


\section{hevistg all pgutg}

\} REFLEXÕES ACERCA DA CONSTRUÇÃO DOS DIREITOS HUMANOS - COSTA, R. R. S. \}

DOI: $10.12957 /$ REP.2017.32752

histórica não pode se dar em etapas, visto que existe uma constante correlação de forças sociais em ação.

Podemos mencionar, como forças sociais e históricas que contribuíram para a construção de um conjunto de direitos, três elementos: o feudalismo, a peste negra e o surgimento da burguesia enquanto classe social. O feudalismo caracteriza-se como um sistema econômico que se baseava em uma rígida estratificação social, fundado no princípio do privilégio de nascimento, no qual o servo, o último estrato da hierarquia social, deveria pagar impostos aos nobres e ao clero. Cabia ao servo uma série de obrigações para com o seu senhor, como, por exemplo, prestar serviços na casa, no castelo e nas igrejas e lutar nas guerras quando convocado (TRINDADE, 2002). Esse sistema baseava-se ainda no uso comum da terra, onde os vassalos plantavam nas áreas produtivas, mas pelo menos um terço da produção deveria ser entregue ao senhor; o restante era destinado à sobrevivência. Além de entregar um terço da produção, eles eram obrigados à corveia (trabalho gratuito), em que o servo e seus familiares tinham que trabalhar dois ou três dias da semana nas terras do senhor feudal.

No feudalismo, o servo diferia do escravo em dois aspectos: a) não poderia ser vendido, pois pertencia à terra, só podendo ser transferido de senhor caso a terra fosse vendida; b) recebia, por parte do senhor, uma parcela dos rendimentos da produção. Devido à forma como funcionava o feudalismo, este se caracteriza por: produzir pouco excedente; ser um modo de produção de subsistência; existir poucas trocas entre os feudos e ser, predominantemente, rural.

A peste negra (1348), segundo Trindade (2002), representou um importante evento histórico impulsionador do direito à liberdade.

A peste negra ficou conhecida na história como uma doença responsável por uma das mais trágicas epidemias que assolaram o mundo Ocidental. Chegando pela Península Itálica, em 1348, essa doença afligiu tanto o corpo, quanto o imaginário de populações inteiras que sentiam a mudança dos tempos por meio de uma manifestação física. Assim como a Aids, a peste negra foi considerada por muitos um castigo divino contra os hábitos pecaminosos da sociedade. (SOUSA, 2017).

Com o despovoamento da Europa Ocidental devido ao grande número de vítimas da peste negra, ocorreu escassez de trabalhadores e, consequentemente, um aumento no valor do trabalho alugado. Os camponeses perceberam nessa situação uma oportunidade de fortalecimento da sua luta, pois naquele contexto tinham como enfrentar os senhores e exigir, através da força, as concessões que não conseguiram conquistar de outra forma. Isso só foi possível porque os camponeses possuíam como moeda de barganha a sua força de trabalho, que se tornava cada vez mais rara, tendo em vista que poucos sobreviveram. Além disso, a peste negra atingiu nobres, clero e plebeus, desconstruindo a ideia de que a nobreza e 


\section{ReVistg QIII PaUtg}

\} REFLEXÕES ACERCA DA CONSTRUÇÃO DOS DIREITOS HUMANOS - COSTA, R. R. S. \}

DOI: $10.12957 /$ REP.2017.32752

os sacerdotes teriam proteção divina. Diante desses elementos, o século XIV foi marcado por convulsões e revoltas camponesas contra os impostos, a fome e as más condições de vida às quais estavam submetidos.

O surgimento da burguesia como uma nova classe social é um dos elementos que contribuíram para o processo histórico de aquisição de direitos civis. Essa classe intermediária era composta por pessoas livres que conseguiram se desvincular do seu senhor ou que haviam fugido ou comprado a sua liberdade. Pessoas vindas de famílias que tinham se dedicado, exclusivamente, às atividades artesanais ou eram funcionários públicos, advogados ou que não possuíam ocupação.

Com o passar do tempo, essa classe foi construindo a sua hegemonia e conseguindo se consolidar. Nos séculos XV e XVI já emprestavam dinheiro aos reis, forneciam assessores para administrar o Estado e estavam envolvidos em todos os negócios que surgiam na época.

Entre os séculos XVII e XVIII, a burguesia já estava bastante diversificada em vários estratos, desde mestre artesão que expandiram suas oficinas contratando muitos empregados e montando manufaturas até grandes (para a época) industriais e banqueiros, e constituía o que pode ser chamado de uma classe média- no sentido de ser intermediário entre a aristocracia e a grande massa do povo. (TRINDADE, 2002, p. 25).

Essa nova classe tinha interesse em ver o declínio do feudalismo, pois a ideologia que predominava impedia a acumulação de riquezas, o lucro, o desenvolvimento do trabalho assalariado (base do capitalismo) e a expansão dos mercados. Os elementos de contradição interna do feudalismo foram as molas propulsoras da sua transformação. A derrocada do feudalismo se deu de forma dialética, processual e inserida em um contexto histórico em que as forças econômicas e sociais o sufocaram, até o ponto em que o sistema deu lugar ao capitalismo e este montou suas bases por dentro do sistema vigente. Esse processo viria a resultar na tomada de poder por parte da burguesia, que tem na Revolução Francesa (1789) o seu ponto máximo, provocando profundas transformações no sistema de direitos.

No tópico seguinte será discutido o contexto histórico em que se desenvolveram os direitos humanos, sendo importante ressaltar que não se trata de um movimento linear, e sim processual, marcado por avanços e retrocessos. Realizamos as divisões em ciclos para destacar os principais elementos de cada momento histórico.

\section{$1.11^{\circ}$ ciclo (séculos XVII e XVIII)}

Segundo Trindade (2002), podemos dividir cronologicamente a aquisição dos direitos humanos em três ciclos: o primeiro ciclo, compreendido entre os séculos XVII e XVIII, está relacionado à construção pro- 


\section{hevistg all pgutg}

\} REFLEXÕES ACERCA DA CONSTRUÇÃO DOS DIREITOS HUMANOS - COSTA, R. R. S. \}

DOI: $10.12957 /$ REP.2017.32752

gressiva de uma nova sociedade diferente da que havia na Idade Média, estando diretamente relacionada aos elementos citados anteriormente. É nesse momento da história que os estados modernos se constituem e ocorre a substituição dos privilégios feudais pelos direitos burgueses.

Quatro marcos históricos foram fundamentais para a aquisição dos direitos civis e políticos: a Revolução Puritana (1640), a Revolução Gloriosa $(1688)^{1}$, a luta pela independência dos EUA (1776) e a Revolução Francesa (1789). Esta última é a mais importante para a conquista de tais direitos, porque projetou os seus ideais para além das fronteiras francesas, ou seja, com ela "os direitos passam a ter um caráter universal" (MONDAINI, 2006, p. 65).

Nesse momento histórico a liberdade é o princípio mais evocado por todas essas revoluções, pois só o ser livre seria capaz de escolher; ou melhor, quando um povo é livre tem possibilidades de escolha e pode construir a sua própria história. Apesar disso, adiantando alguns elementos da crítica de Marx (2009), essa liberdade posta pelas revoluções burguesas está intrinsecamente vinculada à sociabilidade capitalista e, por esse motivo, só pode ser exercida dentro das limitações que ela impõe. Somente a emancipação humana permitiria ao ser humano vivenciar uma liberdade plena e sem restrições.

A Declaração dos Direitos dos Homens e do Cidadão, promulgada durante a Revolução Francesa, segundo Trindade (2002), é o atestado de óbito do regime feudal, pois rompe com algo que fundamentava aquele sistema: o privilégio de nascimento.

Os homens nascem e são livres e iguais em direitos (artigo $1^{\text {o}}$ ) e 'a finalidade de toda associação política é a conservação dos direitos naturais e imprescindíveis do homem' ( $2^{\circ}$ artigo). Quais são esses direitos? São quatro: 'a liberdade, a propriedade, a segurança e a resistência à opressão ( $2^{\circ}$ artigo $)^{\prime}$.

A soberania foi atribuída, no artigo 3o à 'Nação' (fórmula unificadora) e não ao povo (expressão rejeitada, pelo que podia conter reconhecimento das diferenças sociais). A liberdade ( $4^{\circ}$ artigo 'pode fazer tudo aquilo que não prejudique a outrem') só pode ser limitada pela lei, que deve proibir as 'ações prejudiciais à sociedade' ( $5^{\circ}$ artigo). A lei 'deve ser a mesma para todos' (6⿳⺈ artigo). (TRINDADE, 2002, p. 53).

O direito à propriedade é o único que na Declaração dos Direitos dos Homens e do Cidadão é considerado como inviolável e sagrado. Sobre esse direito, Karl Marx (2009) faz uma crítica, já que a propriedade privada é a base de exploração de um homem sobre o outro. O direito de ter propriedade estabelece uma igualdade jurídico-formal, em que todos possuem

\footnotetext{
${ }^{1}$ Segundo Trindade (2002, p. 81), essa revolução foi o coroamento de um longo processo histórico de disputas da aristocracia e da burguesia inglesas contra os seus reis.
} 


\section{ReVistg QIII PaUtg}

\} REFLEXÕES ACERCA DA CONSTRUÇÃO DOS DIREITOS HUMANOS - COSTA, R. R. S. \}

DOI: $10.12957 /$ REP.2017.32752

o direito de ser proprietários, mas que não garante as condições para que todos o sejam.

A defesa da propriedade privada é basilar, tendo em vista que a declaração daqueles direitos foi proposta por uma classe com interesses específicos e que tinha como base de fortalecimento e consolidação a propriedade. Já a igualdade não está no rol dos direitos naturais e tampouco foi elevada ao patamar de inviolável e sagrada. Isso porque os direitos civis possuem um claro direcionamento de classe. A igualdade está inscrita apenas no plano jurídico; ela não é extensiva ao âmbito social, ou seja, a Declaração dos Direitos dos Homens e do Cidadão não questionou a desigualdade econômica que assolava a França naquele momento, pois possuía o interesse de assegurar que a burguesia seria a classe dirigente do novo sistema que se constituía.

\section{$1.22^{\mathrm{o}}$ ciclo (séculos XIX e XX)}

O segundo ciclo, situado entre o século XIX e início do XX, está relacionado às lutas da classe trabalhadora, inspirado pelo pensamento socialista, centrado na figura de Karl Marx. Nesse ciclo, há uma crítica à forma como o modelo socioeconômico se configurava com a produção social e a apropriação privada da riqueza socialmente produzida. Em consequência, criou-se um ambiente de insatisfação, com uma pequena parcela social se tornando cada vez mais rica e a pobreza se generalizando entre os demais.

O primeiro entendimento da "questão social", enquanto manifestação da luta de classe do proletariado e a luta contra a apropriação privada, está relacionado às Revoluções de 1848, representando um momento em que a classe trabalhadora se organizou para reivindicar os seus direitos, explicitando, assim, um conflito entre classes. Os ideários das Revoluções de 1848 questionavam os Estados absolutistas, que foram substituídos pelas repúblicas democráticas, além de questionarem a ordem econômica e de fazerem uso revolucionário do termo "questão social".

Diante desse cenário, iriam se configurar algumas perspectivas teóricas para responder às indagações da classe trabalhadora. Os socialistas utópicos, como Proudhon e Saint-Simon, propunham formas utópicas de concretizar o socialismo.

O cenário de nascimento do socialismo utópico, a França do início do século XIX, abundavam as crises provocadas pelo avanço do sistema liberal, que produzia miséria em série, proporcionando precárias condições de vida aos cidadãos que então chegavam recentemente do meio rural. A jornada de trabalho absurda e o uso de mão de obra infantil completavam o cenário de horror que a Revolução Industrial criou inadvertidamente. Nesse ambiente onde as promessas da Revolução Francesa acabaram de certo modo por não se concretizar, onde a única liberdade existente era a de mercado, com o capitalista tendo passe livre para 
realizar a exploração do trabalhador comum. De tal decepção e frente à uma realidade desesperadora, surgem os questionamentos por parte dos intelectuais. De uma dessas correntes de questionamentos temos a origem do socialismo utópico. O termo 'utopia' é um resgate literário do título do livro de Thomas Morus, de 1516, e tal expressão passa assim a designar toda filosofia defensora da igualdade social, onde era pregado um modelo idealizado, mas a "receita" para se atingir tal caminho não era discutida. (SANTIAGO, 2006).

Na visão defendida por Marx e Engels (1848), somente a emancipação humana e a ruptura com a ordem capitalista poderiam pôr fim ao conflito irreconciliável das classes sociais: a exploração da força de trabalho e a propriedade privada.

A partir dos questionamentos da classe trabalhadora, o sistema capitalista se viu obrigado a responder às demandas sociais do proletariado, pois o acirramento da contradição entre capital e trabalho poderia pôr um fim ao sistema vigente. Essa resposta, através dos direitos sociais, é contraditória, porque, ao mesmo tempo em que esses direitos são fruto da luta histórica dos trabalhadores, também contribuem para a consolidação e o fortalecimento do capitalismo.

As respostas dadas pelo Estado para as demandas de reprodução social da classe trabalhadora são fundamentais para desresponsabilizar o capital de arcar com esses custos, além de responder de forma imediata e paliativa, sem afetar diretamente as raízes da questão. Portanto, o Estado atende às reivindicações da classe trabalhadora, mas na mesma proporção arrefece as lutas, uma vez que há, nesse campo de batalha, uma conciliação de classes que se dá em torno das concessões feitas pelo Estado e pela classe dominante, da qual ele é o representante.

Fazendo um contraponto, nos países do chamado "socialismo real", os direitos sociais foram incorporados como sendo direitos inalienáveis dos homens, mas, para que eles fossem realmente efetivados, os direitos civis e políticos foram restringidos. Ou seja, o processo histórico vem nos mostrar que, para que um direito seja adicionado, outro pode ser excluído. Para ilustrar, no Manifesto comunista, Marx e Engels (1848) são claros ao afirmar que, para haver uma sociedade na qual todos tenham direito à igualdade, faz-se necessário o fim da propriedade privada. Isso excluiria um direito, considerado pelos liberais como natural e inalienável.

Por essa razão, entendemos que a hegemonia e a direção de uma determinada classe representam uma chave importante para compreensão dos direitos, pois a aquisição e a consolidação de direitos estão relacionadas com a luta de classes. Não se pode querer adicionar direitos de igualdade e equidade em uma sociedade que está sob as bases do capitalismo. Tais propósitos colocariam em cheque um elemento estrutural: a propriedade privada; logo, o Estado burguês e a burguesia fazem concessões, desde que essas não extrapolem os limites do capital e não representem uma ameaça. 


\section{$1.33^{0}$ ciclo (segunda metade do século $X X$ até os dias atuais)}

O terceiro ciclo, situado a partir da metade do século XX, é marcado pela luta dos direitos sociais, políticos e civis para aqueles grupos chamados de "deserdados" (TRINDADE, 2002) e que não eram considerados iguais, embora o fossem perante a lei. Como exemplo, podemos citar: mulheres, homossexuais, negros, trabalhadores pobres dos países subdesenvolvidos e dominados pelas potências imperialistas, bem como as crianças, que até então não eram consideradas sujeitos de direitos. Em outras palavras, esse ciclo representa a luta pelos direitos das minorias políticas. É nesse momento que nomes importantes, como o de Mahatma Gandhi, Nelson Mandela e Martin Luther King, destacam-se pelas lutas pacíficas que empreenderam na defesa dos grupos oprimidos e na luta para que pudessem viver com igualdade de direitos perante os demais.

É característica desse ciclo a mobilização em prol de novos direitos relacionados às questões ambientais, exigindo a sua preservação e o recuo da ação predadora do homem; o fim da corrida armamentista empreendida por EUA e URSS no pós-II Guerra Mundial; e o término do acúmulo de armas de destruição em massa. Esse período da história também se define pela incorporação dos direitos dos povos que vivem subjugados às ações dos Estados despóticos, totalitários e imperialistas, e que podem ser vítimas de genocídios cruéis e bárbaros, visando assegurar a sua dignidade e barrar atos violentos contra grupos de mulheres, crianças, negros e religiosos. $\mathrm{O}$ que se percebe de fundamental neste ciclo é a exigência de uma democracia que assegure direitos para todos e que não sejam restritos a uma elite, embora essa exigência prescinda o questionamento do capitalismo.

Depois da II Guerra Mundial, em 26 de junho de 1945, foi criada, através da Carta de São Francisco, a Organização das Nações Unidas (ONU). Essa organização tem como finalidade: promover e praticar a tolerância e a convivência em paz com os outros vizinhos; unir forças para manter a paz e a segurança internacionais, garantindo que as forças armadas só sejam utilizadas quando for de interesse comum; e promover o progresso social e econômico de todos os povos. Em seu 1ำ artigo, a Carta de São Francisco estabelece:

1. Manter a paz e a segurança internacionais e, para esse fim: tomar, coletivamente, medidas efetivas para evitar ameaças à paz e reprimir os atos de agressão ou outra qualquer ruptura da paz e chegar, por meios pacíficos e de conformidade com os princípios da justiça e do direito internacional, a um ajuste ou solução das controvérsias ou situações que possam levar a uma perturbação da paz;

2. Desenvolver relações amistosas entre as nações, baseadas no respeito ao princípio de igualdade de direitos e de autodeter- 


\section{hevistg all pgutg}

\} REFLEXÕES ACERCA DA CONSTRUÇÃO DOS DIREITOS HUMANOS - COSTA, R. R. S. \}

DOI: $10.12957 /$ REP.2017.32752

minação dos povos, e tomar outras medidas apropriadas ao fortalecimento da paz universal;

3. Conseguir uma cooperação internacional para resolver os problemas internacionais de caráter econômico, social, cultural ou humanitário, e para promover e estimular o respeito aos direitos humanos e às liberdades fundamentais para todos, sem distinção de raça, sexo, língua ou religião; e

4. Ser um centro destinado a harmonizar a ação das nações para a consecução desses objetivos comuns. (ONU, 1945.).

Esses foram os princípios que configuraram a Declaração Universal dos Direitos Humanos em 10 de dezembro de 1948, na Assembleia Geral das Nações Unidas. O documento passou a considerar os direitos econômicos, sociais e culturais como direitos humanos, ou seja, a partir de 1948 o conjunto dos direitos a serem garantidos a todos os povos havia se ampliado e não estava mais restrito aos direitos civis e políticos. Isso só foi possível porque a então União Soviética conseguiu conquistar muitos aliados na Europa, formando o que ficou conhecido como campo socialista, e também porque o movimento dos trabalhadores havia ressurgido das cinzas do fascismo por toda a parte. Logo, a ONU não poderia desconsiderar as opiniões do campo socialista, o que possibilitou a participação ativa no processo de redação da Declaração Universal dos Direitos Humanos.

O cerne da Declaração de 1948 consiste no reconhecimento de que compõe o âmbito dos direitos humanos todas as dimensões que disseram respeito à vida com dignidade - portanto, em direito, deixam de fazer sentido qualquer contradição, ou hierarquia, ou 'sucessão' cronológica ou supostamente lógica entre os valores da liberdade (direitos civis e políticos) e da igualdade (direitos econômicos, sociais e culturais). Sob o olhar jurídico, os direitos humanos passaram a configurar uma unidade universal, indivisível, interdependente e inter-relacionada. (TRINDADE, 2002, p. 191).

Segundo Trindade (2002), a Declaração Universal dos Direitos Humanos (1948) inaugurou o direito internacional, haja vista que, até o momento, não havia nenhum documento materializado que tratasse do assunto com tanta abrangência. Além disso, contribuiu para integrar os direitos econômicos, sociais e culturais (adquiridos no contexto das revoluções socialistas) aos direitos civis e políticos (conquistados no contexto das revoluções liberais).

Desse modo, compreende-se que o conjunto de direitos humanos conquistados atualmente é resultado de uma intensa luta de classes e de disputas de interesses no decorrer do processo histórico. A classe trabalhadora não pode se restringir a lutar por mais direitos, mas deve ter como horizonte a consolidação da sociedade regulada, conforme os termos 


\section{ReVistg all paltg}

\} REFLEXÕES ACERCA DA CONSTRUÇÃO DOS DIREITOS HUMANOS - COSTA, R. R. S. \}

DOI: $10.12957 /$ REP.2017.32752

de Antonio Gramsci (apud BIANCHI, 2008). Isso porque a mera luta por mais direitos não irá concretizar a emancipação humana, tendo em vista que a ideologia que norteia as classes em disputa é diametralmente oposta. Não é possível lutar por direitos e não questionar o capitalismo, pois, enquanto permanecermos nos limites do capital, os direitos sempre serão contraditórios e disputados pelas classes sociais. É a hegemonia de uma classe sobre a outra que indica para qual direção esses direitos estão apontando.

Considerando que, para Marx (2009), a emancipação humana é um eixo central, a crítica tecida no ensaio $A$ questão judaica irá denunciar que os direitos estão limitados à sociedade burguesa e inscritos no campo da emancipação política. A luta e a aquisição de direitos, encerrados em si mesmos, não conseguem operar a emancipação humana.

\section{Crítica marxista sobre os direitos}

O ensaio A questão judaica, publicado em 1844, representa o ato de fundação da crítica marxista aos direitos. O texto é uma crítica à análise de Bruno Bauer sobre a emancipação política dos judeus no Estado laico. Nele, Karl Marx (2009) faz duas diferenciações importantes: 1) emancipação política e emancipação humana; 2) direitos do homem e direitos dos cidadãos. A partir da cisão do homem, teremos os direitos do homem e os direitos do cidadão.

Na primeira diferenciação, Marx (2009) esclarece que a emancipação política se dá em relação à religião ou à propriedade privada, ou seja, o Estado se abstrai do homem e transfere a crença religiosa da esfera pública para a privada, mas isso não significa que o homem seja emancipado humanamente. Em A crítica da filosofia do direito de Hegel (2005), Marx (2005) já colocava a emancipação política como sendo uma revolução parcial, em que apenas uma parte da sociedade se torna emancipada: a burguesia. Esta impõe sobre o resto da sociedade sua hegemonia, passando a ser a representante da vontade geral.

A emancipação humana só será plena quando o homem real e individual tiver em si o cidadão abstrato; quando como homem individual se tiver tornado um ser genérico, e quando tiver reconhecido e organizado as suas próprias forças como forças sociais, de maneira a nunca mais separar de si esta força social como força política. (MARX, 2009, p. 30).

Compreende-se, portanto, que o fato de o Estado ter se tornado laico não significa necessariamente que os homens sejam livres. No plano privado, individual, egoísta e independente, ele continua sendo religioso, o que seria o motivo da sua alienação. Assim, e igualmente, o fato de a democracia ter superado os limites do voto censitário não seria suficiente para libertar o homem da propriedade privada, pois esta se manteria legitimada 


\section{hevistg all pgutg}

\} REFLEXÕES ACERCA DA CONSTRUÇÃO DOS DIREITOS HUMANOS - COSTA, R. R. S. \}

DOI: $10.12957 /$ REP.2017.32752

no interior da sociedade civil burguesa. É por esse motivo que, em A crítica da filosofia do direito de Hegel (2005), Marx (2005) coloca a democracia no plano da emancipação política, já que ela opera meramente uma transformação na forma política da república burguesa, em que, aparentemente, todos poderão participar em igualdade de condições e terão suas necessidades consideradas pelo Estado.

A emancipação política realiza meramente uma transferência dos elementos de alienação do plano público para o privado. Essa transferência provoca uma cisão entre os homens: público e privado. Segundo Marx (2009), o homem leva uma dupla existência: ora vive na comunidade política, como ser comunitário; ora na sociedade civil, como indivíduo privado. Isso é diferente da emancipação humana, que, nas palavras de Karl Marx (2009), só acontecerá quando a classe consistir em um agente político idealista que se sinta representante das necessidades sociais em geral.

A partir dessa cisão do homem, teremos os direitos do homem e os direitos do cidadão. De um lado, os direitos do homem, egoístas, individuais, independentes da comunidade e ligados a interesses pessoais. De outro, os direitos do cidadão, pertencentes a uma comunidade política, da qual, juntamente com os outros, o homem faz parte. Ao indicar essa cisão e, por conseguinte, dos respectivos direitos, podemos afirmar que Marx (2009) faz uma diferenciação entre o direito privado, do homem egoísta, e o direito público, do cidadão. Karl Marx (2009) afirma que os direitos do cidadão são subordinados aos direitos do homem egoísta.

A emancipação política, no sentido de separar o público do privado, apenas consolidou a vida burguesa sem criticá-la, ou seja, não denunciou que na democracia política ou no Estado de direito o cidadão não passa de um ser abstrato e submisso ao homem burguês. Desta forma, o indivíduo não consegue ter consciência de que o cidadão é apenas uma forma velada do homem egoísta.

Daí a conclusão de Marx de que, por meio da emancipação política, o homem é apenas e tão somente reduzido, de um lado, a membro da sociedade burguesa, a indivíduo egoísta, independente e, de outro lado, a cidadão do Estado, a pessoa moral, cabendo à emancipação humana a tarefa histórica desalienante de fazer com que o homem individual real recupere em si o cidadão abstrato, convertendo-se assim, como homem individual, em ser humano genérico. (MONDAINI, 2013, p. 29).

Para Marx (apud MONDAINI, 2011), os direitos delimitavam apenas as liberdades, com o objetivo de evitar o Estado hobbesiano de "guerra de todos contra todos". A delimitação ocorria por meio da afirmação das individualidades, da segurança, da propriedade privada e do ocultamento da exploração na relação de compra e venda da força de trabalho. As formalizações dos direitos permitem que a exploração burguesa se apresente como um direito e não mais como um privilégio, como acontecia na socie- 


\section{ReVistg QIII PaUtg}

\} REFLEXÕES ACERCA DA CONSTRUÇÃO DOS DIREITOS HUMANOS - COSTA, R. R. S. \}

DOI: $10.12957 /$ REP.2017.32752

dade feudal, na qual senhores e servos tinham uma relação de deveres e obrigações. Agora, o burguês se livra das obrigações para com o trabalhador e passa a ter o direito de expropriar a mais-valia produzida, porque paga um salário para esse operário, o que lhe confere o direito de usufruir da sua força de trabalho durante um determinado período.

Alguns pensadores da tradição marxista concordam com a crítica de Marx (2009) de que os direitos seriam uma forma velada da submissão do cidadão ao homem egoísta, mas, como a realidade é dinâmica e dialética, avançaram em outras questões. Antonio Gramsci (apud BIANCHI, 2008), por exemplo, percebeu que o Estado capitalista não se restringe somente ao aparelho coercitivo das classes dominantes, mas apresenta-se como um complexo formado por dois planos que estão organicamente relacionados: 1) a sociedade civil, formada por instituições responsáveis pela construção da hegemonia; 2) a sociedade política, formada por instituições responsáveis pela coerção.

Essa concepção mais ampla do Estado é fundamental, pois permitiu que Gramsci indicasse outros caminhos para a revolução. Segundo ele, em países onde a sociedade civil e política são equilibradas, há possibilidade de uma luta pela hegemonia. Ou seja, uma batalha de ideias em que existe a perspectiva do confronto entre projetos societários divergentes, o que quer dizer que a mudança poderia ocorrer a partir da escola, dos sindicatos, da imprensa etc. Já em países onde a sociedade política se sobrepõe à sociedade civil, a única via de disputa seria a insurreição (MONDAINI, 2011).

Dentro desse contexto, nas análises gramscianas, o direito estaria situado ainda no plano da 'sociedade política'. Isso fica claro quando Gramsci afirma que o 'aparelho da coerção estatal [...] assegura 'legalmente' a disciplina dos grupos que não 'consentem', que o 'domínio direto' [...] se expressa no Estado e no governo 'jurídico' (GRAMSCI apud MONDAINI, 2013, p. 32).

Para Gramsci (apud MONDAINI, 2013), o direito não está inserido no campo da batalha de ideias, da luta por hegemonia, mas sim na esfera da coerção do Estado e da dominação de classes.

Eis, aí, o progresso e o limite contidos nas conclusões presentes na obra do pensador sardo. De uma parte, ele avançou na percepção das estruturas políticas do novo Estado capitalista, das novas relações estabelecidas entre governantes e governados, e das maneiras de transformálas. De outra parte, ele não conseguiu superar a visão tradicional do direito como instrumento auxiliar da dominação de classe. (MONDAINI, 2013, p. 32).

Segundo Claude Lefort (1983), haveria uma limitação histórica do pensamento de Marx, considerando que ele não pôde acompanhar a ampliação dos direitos humanos, restritos aos direitos civis. Segundo Lefort 


\section{hevistg all pgutg}

\} REFLEXÕES ACERCA DA CONSTRUÇÃO DOS DIREITOS HUMANOS - COSTA, R. R. S.

DOI: $10.12957 /$ REP.2017.32752

(1983), à medida que os direitos humanos seriam um importante instrumento de auxílio na dominação de classe, seriam, também, uma importante ferramenta para contenção dos excessos cometidos e o abuso de poder das classes dominantes (MONDAINI, 2011). O direito que reitera a exploração é o mesmo que freia e impõe limites a ela.

A conquista dos direitos políticos e sociais pelas classes subalternas só foi possível porque os direitos civis de liberdade e igualdade jurídico-formais permitiram reivindicar os demais direitos. Logo, o entendimento sobre os direitos é contraditório, pois, à medida que eles legalizam a dominação e a exploração de classes, proporcionam uma mediação legal entre opressores e oprimidos, permitindo que os conflitos não sejam mais reconciliados por um poder arbitrário. Nesse sentido, os direitos humanos se apresentam como um instrumento necessário para conter as investidas e avanços da exploração capitalista e da sociedade burguesa, que degradam a dignidade humana.

Embora o direito, para Marx (2009), represente uma forma de mascarar as relações burguesas, é necessário compreender que as conquistas por mais direitos pode dar novos rumos à história, não se fazendo necessário aguardar uma resolução global dos conflitos ou o momento oportuno de tomar o poder. A mudança de rumos pode ocorrer através da luta progressiva e organizada dos grupos sociais no sentido de manter os direitos já conquistados e de conquistar novos direitos, pois, para que os ideais transformadores se efetivem na realidade, faz-se necessário que um grande número de pessoas os coloquem em prática e estejam convencidas de que eles reiteram e estão na mesma direção dos seus interesses e lutas coletivas.

Diante do que até aqui foi posto, compreende-se que é necessário atualizar a crítica marxiana feita no ensaio A questão judaica, uma vez que, naquele contexto, os direitos se restringiam aos direitos civis e os direitos políticos e sociais ainda não haviam sido incorporados aos direitos do homem e do cidadão.

Em suma, para Marx, os direitos humanos seriam o instrumento da conquista da emancipação política, enquanto tais não passariam de um produto da sociedade burguesa, na qual a conquista da liberdade do indivíduo implica sempre a limitação dos outros indivíduos e não a sua realização junto aos outros [...]. Com isso, a escravidão da sociedade burguesa ganharia a aparência da sua maior liberdade "isso, através da substituição do que antes era privilégio pelo direito. (MONDAINI, 2011).

Portanto, embora a crítica de Marx (2009) aos direitos civis precise ser atualizada, é importante pontuar que a teoria marxista continua sendo um caminho metodológico importante para a apreensão da história social desses direitos, pois busca identificar elementos de determinação no sentido de apreender a totalidade e as condições objetivas para a construção e o surgimento desse conceito. O método de análise de Marx (2009) permite 


\section{ReVistg QIII PaUtg}

\} REFLEXÕES ACERCA DA CONSTRUÇÃO DOS DIREITOS HUMANOS - COSTA, R. R. S. \}

DOI: $10.12957 /$ REP.2017.32752

identificar as forças sociais que interferiram em diferentes momentos, com o objetivo de compreender os motivos que impulsionaram, retardaram e modificaram o desenvolvimento e a prática dos direitos humanos em diferentes sociedades.

\section{Conclusão}

Na contemporaneidade, direitos humanos significam um conjunto de direitos que devem ser assegurados a todos os seres humanos, independente das suas diferenças biológicas, econômicas e culturais. A universalização dos direitos humanos encontra-se localizada em um processo de incorporação de direitos que foi ocorrendo ao longo da história. Essas conquistas são fruto de lutas sociais que resultaram na aquisição de direitos civis, políticos, sociais e dos povos, embora seja importante ressaltar que esse processo não foi concluído e que as lutas sociais para afirmação e ampliação desses direitos devem ser constantes e permanentes.

No século XXI, as divergências ainda persistem, já que o capitalismo e a sua mundialização se opõem ao desenvolvimento de um sistema global de direitos humanos. Isso se dá pois o modo de ser capitalista exige que cada vez mais o sujeito se concentre no ter, no desenvolvimento pessoal e na individualidade, já que cada um precisa conquistar o seu lugar no mundo, nem que para isso o outro seja apenas um meio. A mundialização econômica permite que países desenvolvidos violem os direitos trabalhistas dos povos de países subdesenvolvidos, levando-os a trabalhar em condições de elevada exploração. Ou seja, o capitalismo financeiro banaliza o ser humano, fazendo deste apenas um meio de obter lucros exorbitantes.

Em contrapartida, os direitos humanos tentam assegurar a todos os homens e mulheres a igualdade e a dignidade, sendo uma ferramenta para enfrentar os avanços perversos do sistema econômico vigente. Concordamos com Marx (apud IAMAMOTO, 2011, p. 19) quando afirma que "a crítica não arranca flores imaginárias dos grilhões para que os homens suportem os grilhões sem fantasia e consolo, mas para que se livre deles e possam brotar as flores vivas". Compreende-se, portanto, que ideias transformadoras e a crítica ao sistema que está posto não são suficientes para transformar a realidade; faz-se necessário, porém, uma postura criativa e propositiva diante do mundo, para que as "flores vivas" cresçam e modifiquem a realidade que está ao nosso redor. Sendo assim, à medida que Karl Marx (2009) faz uma crítica aos direitos civis, ele oferece elementos para uma compreensão rica e interessante desse conceito, permitindo uma apreensão dos elementos e determinações que implicam na construção e na prática dos direitos humanos.

Além disso, permite-nos entender que, nos dias atuais, não é possível lutar para ampliação ou manutenção dos direitos sem questionar o ca- 


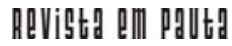

\} REFLEXÕES ACERCA DA CONSTRUÇÃO DOS DIREITOS HUMANOS - COSTA, R. R. S. \}

DOI: $10.12957 /$ REP.2017.32752

pitalismo e os elementos estruturais que possibilitam a sua sobrevivência. A classe subalterna precisa radicalizar as lutas, e não somente permanecer no campo da negociação de classe. Com isso, não estamos diminuindo a importância da luta por direitos, mas reiterando que somente ela não será capaz de conduzir a realidade social para um momento em que todos poderão ser de fato iguais, livres, não sendo igualdade e liberdade meramente jurídico-formais.

O Estado, que, nas palavras de Chico de Oliveira (1984), institucionaliza as regras do jogo, tem sido uma das vias pelas quais as classes dominantes oprimem ainda mais as classes subalternas, através de um aparato legal que retira direitos e restringe, sobretudo, a distribuição da riqueza socialmente produzida. 
\} REFLEXÕES ACERCA DA CONSTRUÇÃO DOS DIREITOS HUMANOS - COSTA, R. R. S. \}

DOI: $10.12957 /$ REP.2017.32752

\section{Referências}

BIANCHI, O laboratório de Gramsci: filosofia, história, política. São Paulo: Alameda, 2008. Disponível em: <https://www.researchgate.net/publication/ 265467970_BIANCHI_Alvaro_O_laboratorio_de_Gramsci_filosofia_historia_politica _Sao_Paulo_Alameda_2008> Acesso em: 09 fev. 2018.

IAMAMOTO, M. V. O Serviço Social na contemporaneidade: trabalho e formação profissional. São Paulo: Cortez, 2011.

LEFORT, C. A invenção democrática. São Paulo: Brasiliense, 1983.

MARX, K. Crítica da filosofia do direito de Hegel. São Paulo: Boitempo, 2005. . A questão judaica. São Paulo: Expressão Popular, 2009.

MARX, K.; ENGELS, F. O manifesto comunista. 1848. Disponível em: <http:/ /www.ebooksbrasil.org/adobeebook/manifestocomunista.pdf>. Acesso em: 12 jul. 2017.

MONDAINI, M. Direitos humanos e marxismo. 2011. Disponível em: <http:// www.acessa.com/gramsci/?page=visualizar\&id=1414>. Acesso em: 12 jul. 2017. . Democracia e direitos humanos sob o fogo cruzado. Recife: Editora Universitária UFPE, 2013.

OLIVEIRA, F. de. A economia da dependência imperfeita. $4^{a}$ ed. Rio de Janeiro: Edições Gerais, 1984.

ONU. Carta das Nações Unidas. 1945. Disponível em: <http://unicrio.org.br/ img/CartadaONU_Versolnternet.pdfl>. Acesso: 12 jul. 2017.

SANTIAGO, E. Socialismo utópico. 2006. Disponível em: <https:// www.infoescola.com/filosofia/socialismo-utopico/>. Acesso em: 9 dez. 2017.

SOUSA, R. G. Peste negra. [2017]. Disponível em: <http://brasilescola.uol. com.br/historiag/pandemia-de-peste-negra-seculo-xiv.htm>. Acesso em: 9 dez. 2017.

TRINDADE, J. D. de L. História social dos direitos humanos. São Paulo: Petrópolis, 2002.

DOI: 10.12957/rep.2017.32752

Recebido em 13 de julho de 2017.

Aprovado para publicação em 29 de novembro de 2017.

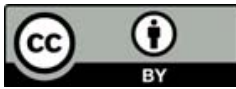

A Revista Em Pauta: Teoria Social e Realidade Contemporânea está licenciada com uma Licença Creative Commons Atribuição 4.0 Internacional. 